\title{
Percutaneous Osteoplasty for the Management of a Talar Metastasis: A Case Report
}

\author{
Mengmeng Chen (D) \\ Hai Tang \\ Fei Feng
}

Department of Orthopaedics, Beijing Friendship Hospital, Capital Medical

University, Beijing, People's Republic of China
Correspondence: Hai Tang

Department of Orthopaedics, Beijing Friendship Hospital, Capital Medical

University, No. 95, Yong an Road,

XiCheng District, Beijing, I00050,

People's Republic of China

Tel +86I360 I362187

Email tanghai@ccmu.edu.cn
Background: Talar metastasis is very rare among all bone metastases. Routine radiotherapy and chemotherapy are the main treatment measures at present. Nevertheless, some patients still experience unbearable cancer pain that cannot be effectively relieved with powerful painkillers. Case Report: We report a patient with advanced renal carcinoma suffering from unbearable pain due to multiple bone metastases that involved several vertebrae (T11, L1, and L2) and the left talus. After percutaneous vertebroplasty in the vertebrae, the pain in the left talus became more prominent. We performed a percutaneous osteoplasty to manage the talar metastasis. Postoperatively, the pain level remarkably decreased, and the patient's activity capacity significantly improved.

Conclusion: Percutaneous osteoplasty is an alternative method for talar metastasis that can alleviate pain immediately and improve the quality of life in patients with advanced malignant tumors.

Keywords: percutaneous osteoplasty, pain, talar metastasis, case report

\section{Background}

Bone metastases that occurred in the hands and feet, known as acrometastases, were first described by Bloodgood in $1920,{ }^{1}$ merely accounting for $0.3 \%$ of all bone metastases. ${ }^{2}$ The incidence in the feet was less than that in the hands. ${ }^{3}$ The calcaneus is the most common place involved in the foot, followed by the talus. ${ }^{3,4}$ As reported, talar metastasis mainly comes from the genitourinary system. ${ }^{3,4}$ Isolated talar metastasis is very rare, and most cases are accompanied by extensive metastases. ${ }^{5}$ The therapeutic schedule of skeletal metastasis was mainly focused on routine radiotherapy and chemotherapy, which may prolong the lives of patients. However, these measures do not reconstruct the stability of areas with osteolytic lesions, which evoke unbearable pain and seriously influence the quality of life of patients. Some studies have reported the use of percutaneous osteoplasty in the vertebrae, humerus and pubic metastases. ${ }^{6,7}$ We report a case of renal clear cell carcinoma accompanied by talar lytic destruction treated with percutaneous osteoplasty, which achieved excellent clinical efficacy.

\section{Case Report}

Written informed consent was obtained from patient's family for publication of this case report. This study was approved by the Beijing Friendship Hospital Ethics Committee. A 56-year-old male complained of unbearable pain in the back and left foot after five rounds of chemotherapy for advanced renal carcinoma. The patient was diagnosed with renal clear cell carcinoma and underwent radical resection one year prior. Then, regular chemotherapy was performed in the following months. However, the patient had 

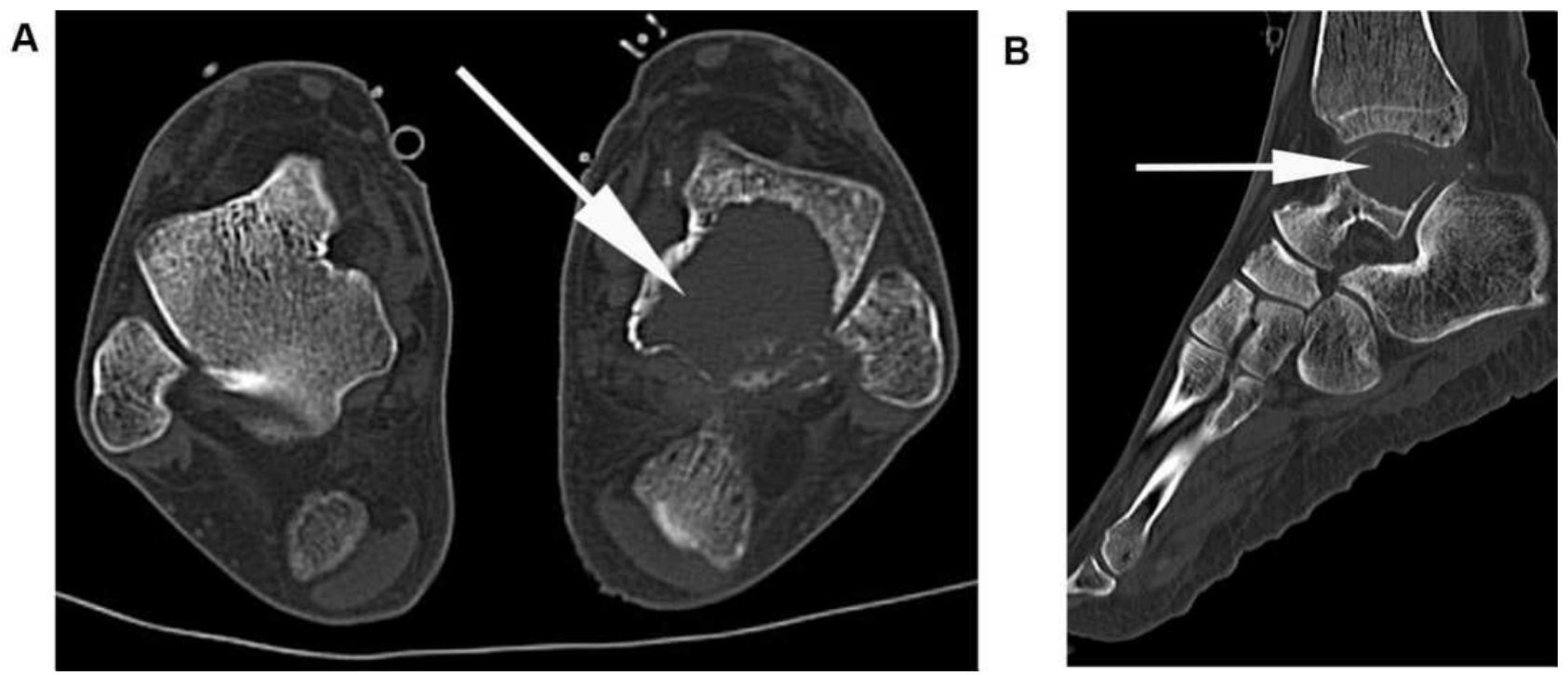

Figure I CT scans indicated osteolytic destruction of the talus. (A). Axial image. (B). Sagittal image.

worsening back and left foot pain, and as a result, he could not step on the left foot for the last two months. There was no obvious redness, swelling or heat around the left ankle. A bone radionuclide scan indicated multiple bone metastases that involved multiple segmental vertebrae (T11, L1, and L2) and the left talus. Therefore, this patient was treated with local radiotherapy and opioids to relieve the pain. Two weeks ago, cancer pain seriously influenced the patient's daily life and sleeping, which could not be controlled by taking powerful painkillers. The patient was admitted to our department. Computed tomography (CT) showed that the left talar body was invaded and had a lytic lesion, which was vulnerable to pathologic fracture (Figure 1). Considering advanced renal carcinoma associated with multiple bone metastases, a palliative schedule was chosen for this patient. The main purpose of this schedule was relieving pain and improving the quality of life, rather than radical surgery to cure the carcinoma. In the first stage, percutaneous vertebroplasty was performed to stabilize the involved vertebrae and alleviate back symptoms. After this procedure, the visual analog scale (VAS) score of the back significantly decreased, and the pain located in the left talus began to be more prominent. In the second stage, percutaneous osteoplasty was performed in the talar body due to persistent pain in the left foot. The detailed operative procedure was as follows (Figure 2). The medial side of the talar body was set as the puncture point. After local anesthetization, the puncture needle $\left(\right.$ Kyphon $^{\circledR}$, Medtronic, CA, USA) was knocked into the talar body under X-ray supervision (notice the depth and position of the needle tip from the perspective of anteroposterior and lateral views). The needle cone was withdrawn when it reached the area adjacent to the contralateral cortical bone. A fine drill was used to expand capacity in all directions. Part of the tissue was removed for pathological examination. After connecting the device, the bone cement was slowly pushed into the talar body. The talar body was gradually filled with polymethyl methacrylate (PMMA; Osteopal V, Heraeus Medical, Wehrheim, Germany) while strictly controlling the volume of bone cement and maintaining an even distribution to prevent bone cement leakage. The working channel was pulled out, and the skin was sutured after completion of bone cement injection. No severe complications, such as bone cement leakage, pulmonary embolism, tendon injury, or infection, occurred during the entire procedure.

After a series of therapies, the VAS score significantly decreased from 9 preoperatively to 3 postoperatively. The Musculoskeletal Tumor Society-93 (MSTS-93) score improved from $30 \%$ preoperatively to $65 \%$ postoperatively. The patient could walk on his left foot without any assistance. We still reminded the patient to reduce the frequency of stepping on the foot. Two weeks after the operation, the VAS score significantly decreased to 2, and the MSTS-93 score improved to $75 \%$. Postoperative $\mathrm{X}$-rays showed that the talar body was filled with bone cement without leakage (Figure 3). Meanwhile, the patient is able to obtain good rest through the entire night without the severe pain that was experienced before the operation. The final pathological result confirmed metastasis originating from renal clear cell carcinoma (Figure 4). Then, the patient was treated with regular radiotherapy and 


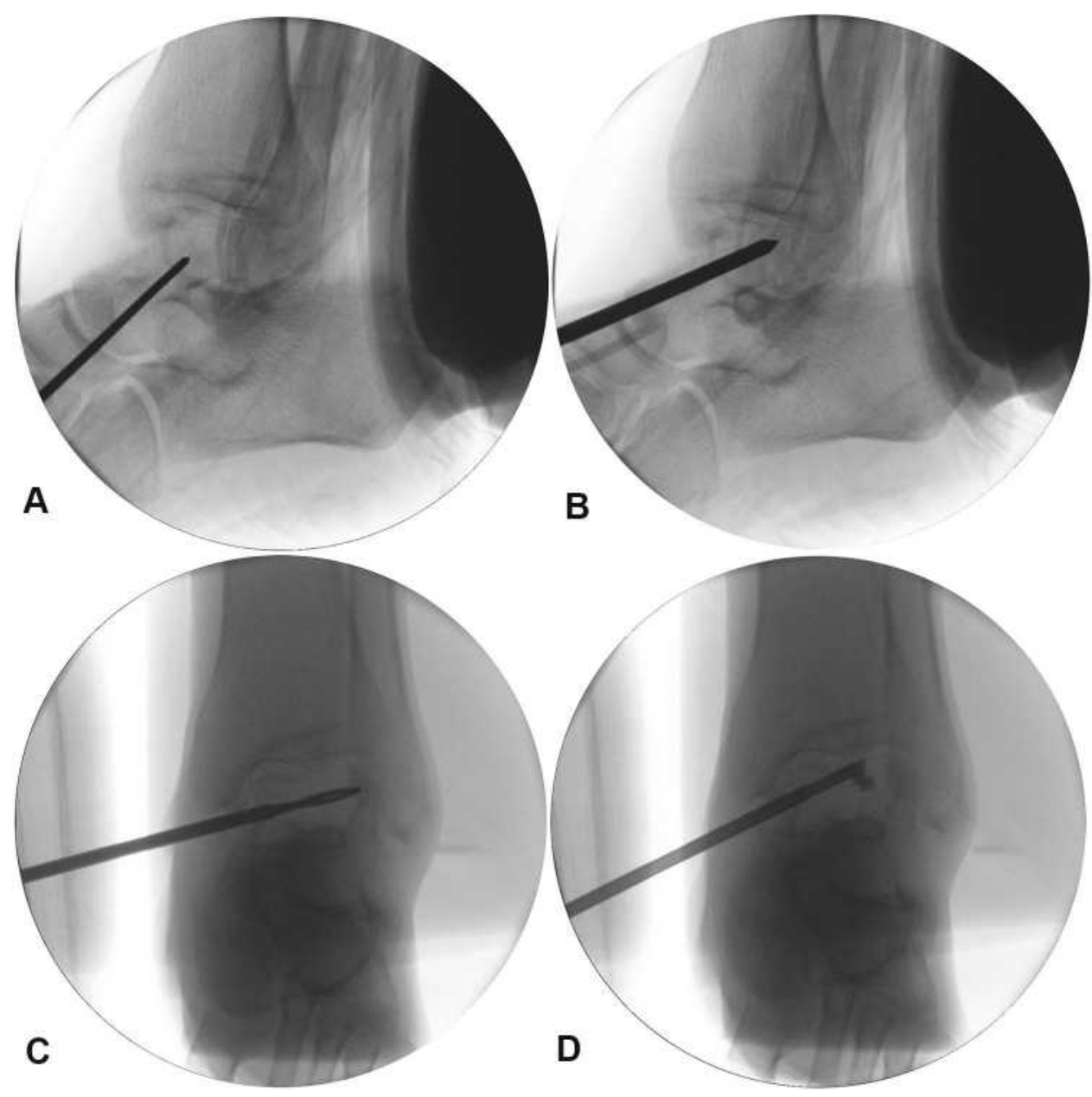

Figure 2 Detailed operative procedures. (A). Puncture needle was knocked into the talar body. (B). The puncture needle reached the area adjacent to the contralateral cortical bone. (C). A fine drill was used to expand the capacity in all directions. (D). The talar body was gradually filled with PMMA. (PMMA, polymethyl methacrylate).

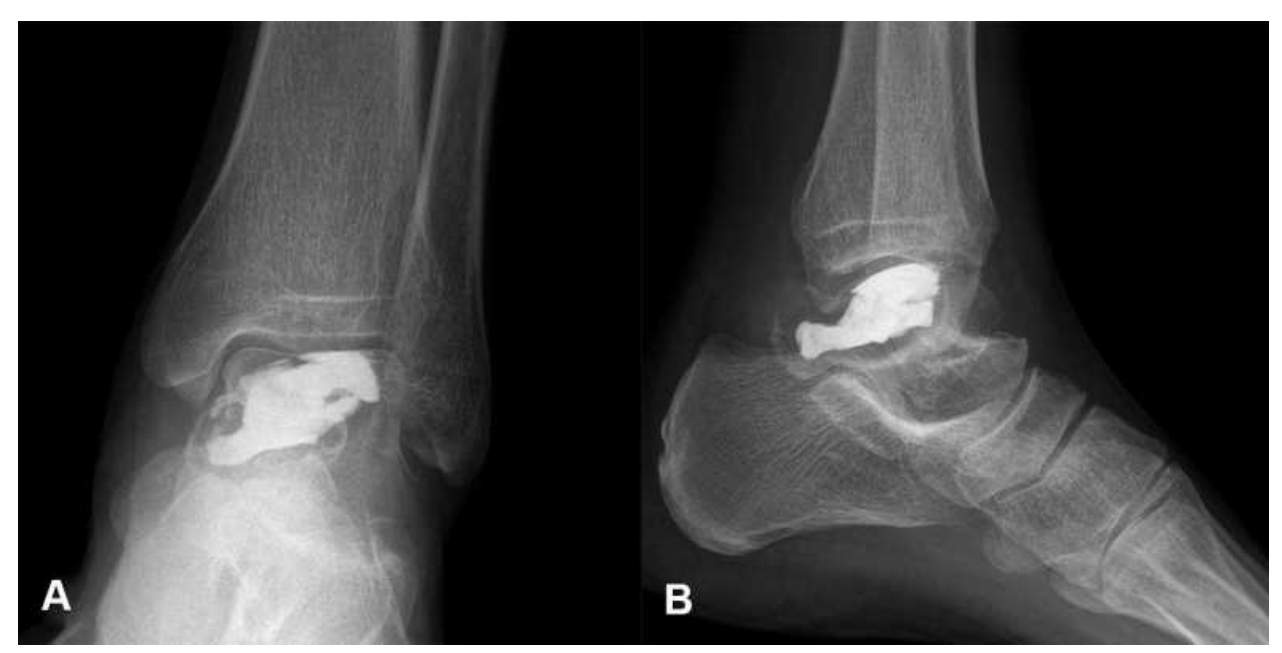

Figure 3 Postoperative X-ray images indicated that the talar body was evenly filled with PMMA. (A). Ankle image from anteroposterior view. (B). Ankle image from lateral view. (PMMA, polymethyl methacrylate). 


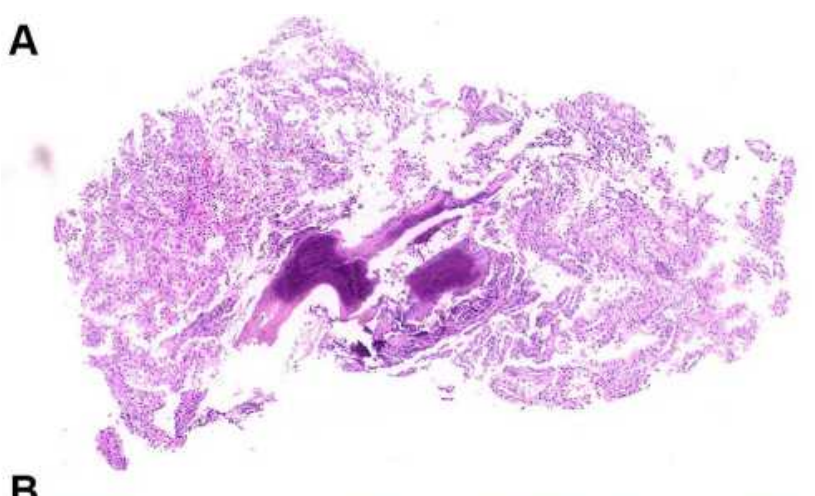

B

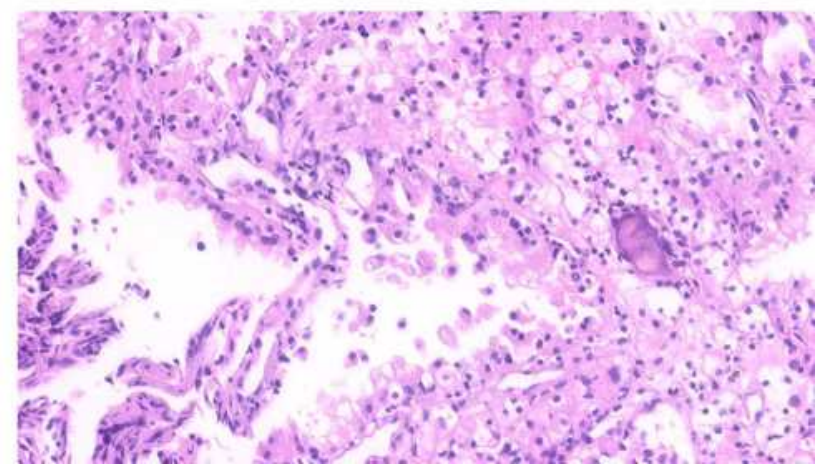

Figure 4 Postoperative histopathological photos confirmed that the lesion originated from renal clear cell carcinoma. (A). magnification $X 40$, hematoxylin and eosin stain. (B). magnification $X 200$, hematoxylin and eosin stain.

zoledronic acid in the following months. Unfortunately, the patient dead due to rapidly disease progression after ten months.

\section{Discussion}

Talar metastasis is mainly derived from the genitourinary system, which may be related to the retrograde descent of tumor cells from the sub-diaphragmatic organs through the iliofemoral veins. ${ }^{8}$ Generally, acrometastases are associated with an inferior prognosis. ${ }^{9,10}$ Barbara Pichi reported that a patient with talar metastasis from buccal mucosa carcinoma received a foot amputation in the advanced period and died after one month. ${ }^{11}$ Johnson published a case of talar metastasis from end-stage rectosigmoid adenocarcinoma who accepted radiotherapy and died ten months after the diagnosis. ${ }^{12}$ John et al reported a case of breast carcinoma accompanied by isolated talar metastasis who accepted regular radiotherapy. After 18 months of talar radiotherapy, the patient died due to subsequent cerebral metastasis. ${ }^{9}$ Considering the shorter life expectancy, over intervention cannot create higher efficacy. Therefore, palliative treatment was the principal goal of relieving pain and improving quality of life.
For isolated talar tumors, the treatment principle was completely different between the primary tumor and metastasis. Huang et al reported a 31-year-old male diagnosed with osteosarcoma of the talus. Then, the patient underwent excision of the entire talus with the insertion of a 3D-printed total talar prosthesis. Finally, this patient achieved excellent functional and clinical outcomes without local recurrence or distant metastasis. ${ }^{13}$ In contrast to primary talar tumors, most patients with talar metastases were in an advanced period.

Several studies have reported the therapeutic regimen of talar metastases. Gan reported a talar metastasis from pulmonary adenocarcinoma, which was first misdiagnosed as a benign bone cyst. A therapeutic schedule of lesion curettage and allogeneic bone implantation was performed. However, the final pathology results indicated that the talar lesion originated from a pulmonary carcinoma. Then, the patient accepted biologic targeted therapy in combination with zoledronic acid, which inhibits the osteoclastic activity of tumor cells. After 12 months of follow-up, the talar body showed an even density without significant bone erosion through radiographic examination. ${ }^{14}$ David Jaffe reported a talar metastasis from breast cancer and performed an open operation to cure the lesion. After freezing residual cancer cells with liquid nitrogen, talar voids were filled with PMMA. After six months, the patient could ambulate with slight pain. ${ }^{15}$

We reported, for the first time, the use of percutaneous osteoplasty to manage talar metastasis. Percutaneous osteoplasty, which is a minimally invasive surgery, can effectively alleviate pain and reduce the dosage of painkillers. Moreover, percutaneous osteoplasty can provide certain stabilization with PMMA filling, which improves the activity capabilities of patients.

There are several explanations about the analgesic mechanism of percutaneous osteoplasty. 6,7 First, the adhesive action of PMMA stabilizes microfractures and reduces stimuli to nerve ending receptors. Second, the polymerized heat produced by PMMA injures some sensory nerve endings. ${ }^{16}$ Third, the monomer released from PMMA is toxic to nerve fibers. Last, the mechanical and chemical effects of PMMA result in tumor tissue or cell damage. ${ }^{17}$

This procedure is similar to percutaneous vertebroplasty, which requires puncture into bone and filling with PMMA. Before the operation, the anatomical structure and lesion location should be carefully analyzed to ascertain the appropriate puncture point to avoid surrounding tissue damage. The puncture point should be set between the tibialis anterior muscle and medial malleolus to avoid repeated puncturing, reducing the risk of tendon damage. During the operation, we should be 
alter to PMMA leakage which could result in serious consequences. Enlarging filling space using a fine drill before the injection of PMMA decrease the infusion pressure. Moreover, the injection of PMMA should be performed slowly with the guidance of X-ray. If there are any signs of leakage, the injection should be immediately stopped. In the procedure, we just harvest a small amount of tissue for pathological examination, not to remove tumor tissue deliberately. Therefore, it is necessary to accept local radiotherapy after percutaneous osteoplasty. Furthermore, zoledronic acid can be used to further inhibit local skeletal destruction.

\section{Conclusions}

Percutaneous osteoplasty is an alternative method for talar metastasis that can alleviate pain immediately and improve quality of life in patients with advanced malignant tumors.

\section{Acknowledgments}

We appreciate the assistance of Dr. Xu for the report of the pathology slides. Patient's relative signed informed consent, and the study was approved by the Beijing Friendship Hospital Ethics Committee.

\section{Disclosure}

The authors report no conflicts of interest in this work.

\section{References}

1. Bloodgood J. Bone tumors, benign and malignant. A brief summary of the silent features based on a study of some 370 cases. Am J Surg. 1920;50:997-998.

2. Zindrick MR, Young MP, Daley RJ, Light TR. Metastatic tumors of the foot: case report and literature review. Clin Orthop Relat Res. 1982;170:219-225.

3. Maheshwari AV, Chiappetta G, Kugler CD, Pitcher JD Jr, Temple HT. Metastatic skeletal disease of the foot: case reports and literature review. Foot Ankle Int. 2008;29(7):699-710. doi:10.3113/ FAI.2008.0699
4. Bakotic B, Huvos AG. Tumors of the bones of the feet: the clinicopathologic features of 150 cases. J Foot Ankle Surg. 2001;40 (5):277-286. doi:10.1016/s1067-2516(01)80063-6

5. Nasr L, Naffaa L, El Alayli A, Abboud MR, Khoury NJ. Isolated delayed metastasis to the talus from Ewing's sarcoma. J Radiol Case Rep. 2018;12(8):17-24. doi:10.3941/jrcr.v12i8.3164

6. Shi G, Tang H. Percutaneous osteoplasty for the management of a pubic bone metastasis. Orthopade. 2019;48(8):704-707. doi:10.1007/s00132-019-03708-7

7. Shi G, Liu Q, Chen H, Feng F, Jia P, Bao L. Percutaneous osteoplasty for the management of a humeral head metastasis: two case reports. Medicine. 2019;98(20):e15727. doi:10.1097/MD.0000000000015727

8. Libson E, Bloom RA, Husband JE, Stoker DJ. Metastatic tumours of bones of the hand and foot. A comparative review and report of 43 additional cases. Skeletal Radiol. 1987;16(5):387-392. doi:10.1007/ BF00350965

9. Kouvaris JR, Kouloulias VE, Papacharalampous XN, Koutselini HA, Gennatas CS, Limouris GS. Isolated talus metastasis from breast carcinoma: a case report and review of the literature. Onkologie. 2005;28(3):141-143. doi:10.1159/000083606

10. Bunkis J, Carter RD. Peripheral bone metastasis from genitourinary tumors. Urology. 1982;19(3):304-305. doi:10.1016/0090-4295(82) 90506-4

11. Pichi B, Marchesi P, Manciocco V, Ruscito P, Pellini R, Cristalli G. Carcinoma of the buccal mucosa metastasizing to the talus. $J$ Craniofac Surg. 2009;20(4):1142-1145. doi:10.1097/SCS.0b013e3181abb469

12. Johnson EW, Janes JM. Metastatic adenocarcinoma of the talus from the rectosigmoid region; report of a case. J Bone Joint Surg Am. 1949;31A(1):181-184. doi:10.2106/00004623-194931010-00020

13. Huang J, Xie F, Tan X, Xing W, Zheng Y, Zeng C. Treatment of Osteosarcoma of the Talus With a 3D-Printed Talar Prosthesis. J Foot Ankle Surg. 2021;60(1):194-198. doi:10.1053/j.jfas.2020.01.012

14. Gan K, Shen Y. Metastatic Pulmonary Adenocarcinoma of the Talus: a Case Report. J Foot Ankle Surg. 2017;56(4):827-831. doi:10.1053/ j.jfas.2017.02.002

15. Jaffe D, Kim E, Aboulafia A. Erosive Breast Cancer Metastasis to the Ankle: a Case Report. J Foot Ankle Surg. 2016;55(6):1297-1301. doi:10.1053/j.jfas.2015.08.003

16. Belkoff SM, Molloy S. Temperature measurement during polymerization of polymethylmethacrylate cement used for vertebroplasty. Spine. 2003;28 (14):1555-1559. doi:10.1097/01.BRS.0000076829.54235.9F

17. Fourney DR, Schomer DF, Nader R, Chlan-Fourney J, Suki D, Ahrar K. Percutaneous vertebroplasty and kyphoplasty for painful vertebral body fractures in cancer patients. J Neurosurg. 2003;98(1 Suppl):21-30. doi:10.3171/spi.2003.98.1.0021
Journal of Pain Research

\section{Publish your work in this journal}

The Journal of Pain Research is an international, peer reviewed, open access, online journal that welcomes laboratory and clinical findings in the fields of pain research and the prevention and management of pain. Original research, reviews, symposium reports, hypothesis formation and commentaries are all considered for publication. The manuscript management system is completely online and includes a very quick and fair peer-review system, which is all easy to use. Visit http:// www.dovepress.com/testimonials.php to read real quotes from published authors.

\section{Dovepress}

